\title{
Impairment of trophic interactions between zebrafish (Danio rerio) and midge larvae (Chironomus riparius) by chlorpyrifos
}

\author{
Miriam Langer-Jaesrich • Cornelia Kienle • \\ Heinz-R. Köhler · Almut Gerhardt
}

Accepted: 29 June 2010/Published online: 14 July 2010

(C) Springer Science+Business Media, LLC 2010

\begin{abstract}
The effects of chemicals on biotic interactions, such as competition and predation, have rarely been investigated in aquatic ecotoxicology. This study presents a new approach for the investigation of predator-prey interactions between zebrafish (Danio rerio) and midge larvae (Chironomus riparius) impaired by chlorpyrifos (CHP), a neurotoxic insecticide. With a simple experimental design including four different treatments: (1) control, (2) predator exposed, (3) prey exposed and (4) both, predator and prey, exposed, we were able to detect by visual observation an increase in the feeding rate of zebrafish preying on exposed chironomids after acute $(2 \mathrm{~h})$ exposure to $6 \mu \mathrm{g} / \mathrm{l} \mathrm{CHP}$. Previously, a decrease in the burrowing behaviour of exposed chironomid larvae was observed. However, when pre-exposing simultaneously
\end{abstract}

Miriam Langer-Jaesrich and Cornelia Kienle have contributed equally to this paper and share first authorship.

M. Langer-Jaesrich $(\varangle) \cdot$ C. Kienle $(\varangle) \cdot$ H.-R. Köhler $(\varangle)$ Department of Animal Physiological Ecology, University of Tübingen, Konrad-Adenauer-Str. 20, 72072 Tübingen, Germany e-mail: langermiriam@gmx.de

C. Kienle

e-mail: cornelia.kienle@gmx.de

H.-R. Köhler

e-mail: Heinz-R.Koehler@uni-tuebingen.de

A. Gerhardt $(\bowtie)$

LimCo International, Oststrasse 24, 49477 Ibbenbüren, Germany

e-mail: Almutg@web.de

Present Address:

C. Kienle

Swiss Centre for Applied Ecotoxicology Eawag/EPFL,

Überlandstrasse 133, 8600 Dübendorf, Switzerland both predators and prey, no significant differences in the feeding rate of zebrafish were observed. This suggests an impairment in prey recognition of the exposed zebrafish. At a lower CHP concentration $(1 \mu \mathrm{g} / \mathrm{l})$, no differences in feeding rate of zebrafish were observed. We therefore propose the use of trophic interactions as parameters in higher tier studies for chemical testing and evaluation of ecotoxicological risk assessment.

Keywords Feeding depression - Pesticide .

Non-biting midge $\cdot$ Fish $\cdot$ Interspecific interaction

\section{Introduction}

Behavioural responses often occur rapidly after exposure to environmental pollutants and represent a sensitive indicator of the influence of pollutants on non target organisms, this being the basis for the rather new branch of behavioural ecotoxicology (Gerhardt 2007). Moreover, pollutantinduced alterations in behaviour affect not only individuals, but also the viability of populations and consequential the structure of ecosystems (Dell' 'Omo 2002). Up to now, the majority of ecotoxicological studies have focused on the direct effect of pollutants on organisms; although indirect effects, such as an impairment of inter- and intraspecific interactions, are also likely consequences of an exposure event. An ecologically important example of interactions in this context is the predator-prey relationship, as food web interactions influence not only the structure of the populations of both directly involved species but might also affect ecosystem functioning (Townsend et al. 2003). According to the optimal foraging theory (Begon et al. 2006), predators exert specific behaviours to detect (searching behaviour) and hunt (handling behaviour) prey organisms, whereas 
the prey develop predator avoidance behaviours in coevolution.

Since the predator prey relationship represents an important biotic interaction it therefore may be susceptible to pollutant exposure. To date, studies of predator-prey interactions in aquatic ecosystems have concentrated mainly on either the predator or the prey. This topic has been addressed in a number of studies up to now, with most investigations aiming at the prey (e.g. Baker and Ball 1995; Brown 2003; Goyke and Hershey 1992; Hershey 1987; Hölker and Stief 2005; Macchiusi and Baker 1992; Schulz and Dabrowski 2001; Sih 1982; Tseng 2003). Only a few studies are available which focus on the predator (e.g. Hamers and Krogh 1997; Power 1990). Grippo and Heath (2003) detected the effects of mercury on the foraging efficiency and capture speed of fathead minnows (Pimephales promelas) exposed to 13 and $57 \mu \mathrm{g} / 1 \mathrm{HgCl}_{2}$. The prey capture rate of mummichogs (Fundulus heteroclitus) in the laboratory was closely related to the diet of the fish in the field, thus representing a biomarker with high ecological relevance. However, due to great variability at the different test sites it was not especially sensitive (Weis et al. 2001).

However, as predator and prey live in the same biocoenosis it is quite likely, that both groups of organisms will be affected by pollution either directly or indirectly. As proposed by Lima (2002), important conclusions about ecological consequences can only be drawn if predators and prey are regarded both equally in the investigation of predator-prey interactions. This approach has been applied in only a few field and laboratory studies with aquatic invertebrates, amphibians and fish (Bridges 1999; Gómez et al. 1997, Rahel and Stein 1988; Taylor et al. 1995; Thorp and Bergey 1981).

In our study we included both, predator (Danio rerio) and prey (Chironomus riparius), to investigate the indirect effect of a pollution scenario (pulse exposure of chlorpyrifos) on the predator prey relationship. To differentiate between effects on predator or prey we used 3 different exposure scenarios: Predator exposed, prey exposed and both predator and prey exposed. A similar exposure design was conducted by Gómez et al. (1997), using different rotifer species. An important difference to this setup is that in our experiment the prey organisms had the opportunity to avoid the predators via burrowing, providing a higher ecological relevance.

As "model" predator we chose the zebrafish (Danio rerio), which naturally occurs in stream habitats rich in macrophytes in South East Asia (Börries 2006). Ecologically, fish represent a very important group of secondary consumers or even top predators.

Our "model" prey organisms were 4th instar larvae of the non-biting midge Chironomus riparius. This organism was chosen because of its ecological importance as food item for fish (Pinder 1986). Chironomids have been used as prey objects for $D$. rerio in many studies and husbandry instructions (Béchard et al. 2008; Lawrence 2007; Nyholm et al. 2008). Additionally as sediment-dwelling organisms, they are particularly susceptible to sediment bound pollutants. There is evidence that chironomids are reacting actively to the presence of predators. For example, studies showed that larvae of $C$. riparius burrowed significantly deeper when exposed to fish kairomones, simulating increasing predator density by Rutilus rutilus (Hölker and Stief 2005). A predatory damselfly, showing visual orientation like fish, fed mostly on chironomids which spent more time out of the tube, i.e. on the sediment surface (Hershey 1987).

As a "model" for an environmentally relevant pollutant we chose chlorpyrifos (CHP), a broad-spectrum organophosphorus insecticide (Richardson 1995). It is one of the most common active compounds in pest control products worldwide (Dow AgroSciences 2010) and is applied in high amounts to agricultural areas of corn, cotton, apples and other orchard crops (Gilliom et al. 2006). In 1990, approx. 1.4 million pounds of this insecticide were applied in the Central Valley of California (Sheipline 1993). In urban streams in the United States, chlorpyrifos concentration exceeded water quality benchmarks in $37 \%$ of the sites (2nd highest exceedance rate after diazinon) and in $21 \%$ of the sites in agricultural streams (highest exceedance rate) during 1992-2001 (Gilliom et al. 2006). Environmental concentrations of $0.19-0.3 \mu \mathrm{g} / \mathrm{l}$ were detected in urban waterways in California and in several surface waters in the USA (Bailey et al. 2000; Gilliom et al. 2006).

Studies so far mainly investigated the effects of chlorpyrifos alone and in mixtures on the acute toxicity to Chironomus tentans and on early-life stage toxicity to zebrafish with different parameters. These included abnormal swimming movements and mortality, among others. However, studies regarding predator-prey interactions with this widely used insecticide are lacking for both invertebrates and for fish.

In the present study the following hypotheses were tested:

1. Exposed chironomids burrow less than control animals, and are therefore more susceptible to predation by fish.

2. Predation by fish stimulates increased burrowing behaviour in exposed as well as control chironomids.

3. When exposing predator and prey, the decreased success of the predator to prey and of the prey to burrow are outweighed, resulting in insignificant differences in feeding rate compared to the control. 


\section{Materials and methods}

In the following experiment zebrafish Danio rerio were used as predators, and larvae of the non biting midge, Chironomus riparius as the prey. The animal maintenance and the experiments were conducted in an acclimatized chamber at $25 \pm 0.5^{\circ} \mathrm{C}$.

Animal culture and maintenance

\section{Chironomus riparius}

Egg ropes of $C$. riparius have been collected from a breeding stock at the University of Tübingen, and kept at $21 \pm 0.5^{\circ} \mathrm{C}$. After hatching, chironomids in the first larval stage (L1) were reared in plastic containers containing dechlorinated tap water and a two centimetre thick layer of quartz sand (particle size $0.1-0.3 \mathrm{~mm}$, burned for $3 \mathrm{~h}$ at $500^{\circ} \mathrm{C}$; Dehner, Germany) under constant aeration. Every day the chironomid larvae of each stock vessel were fed ad libitum with fine powderized ground fish flakes (50\% Tetramin, 50\% Tetraphyll, Tetra, Germany). Dechlorinated tap water was exchanged once a week. For acclimation to the final test conditions, $C$. riparius larvae (L1) were kept in a climate chamber at $25 \pm 0.5^{\circ} \mathrm{C}$ for ten days until they reached the L4 stage. After 10 days larvae reached the L4 stage and were used for the predator-prey experiment.

\section{Danio rerio}

The 4-6 month old Danio rerio (total length: $27.93 \pm$ $3.95 \mathrm{~mm}$ ) used in our experiments were partly the offspring of wild-type zebrafish from the strain WIK (ZFIN ID: ZDB-GENO-010531-2) and wild-type zebrafish from the strain Tue.G14 (generously provided by the MaxPlanck-Institute for Developmental Biology in Tübingen). The fish were kept in aerated and filtered aquaria with a minimum of 1 litre of water per fish. Culture conditions were $25 \pm 0.5^{\circ} \mathrm{C}$ at a $12: 12 \mathrm{~h}$ light:dark cycle. The adult fish were fed twice per day with dry flake food and frozen small crustaceans, Tubifex or midge larvae, respectively. Fish had up to 1 month time for acclimatisation to the new environment. To become acquainted with the prey objects, $D$. rerio was fed during that time with living $C$. riparius larvae several times before the start of the experiment.

\section{Test substance}

Chlorpyrifos (Pestanal, analytical standard, Sigma-Aldrich, Germany) was dissolved in reconstituted water (OECD 1992). In order to prepare a stock solution it was constantly stirred for a minimum of $4 \mathrm{~h}$ at a water temperature of about $45^{\circ} \mathrm{C}$ and a pH of 8.0. Subsequently, the solution was kept at $35^{\circ} \mathrm{C}$ overnight until use with constant stirring. From this stock test solutions were prepared directly before use with dechlorinated tap water. In order to simulate possible pulse pollution concentrations, nominal test concentrations for exposure experiments were 1 and $6 \mu \mathrm{g} \mathrm{CHP/l}$. The retrieval rate for chlorpyrifos in an earlier study with the same experimental setup for stock solution preparation was $51.8 \%$ in analytical measurements (Kienle et al. 2009).

\section{Experimental design}

\section{Preliminary tests}

First, the burrowing behaviour of $C$. riparius in the L4 stage has been observed (unpublished data) as follows: The natural burrowing behaviour of $C$. riparius L4 larvae was assessed in three replicate treatments with 50 chironomids each. The numbers of totally visible and partly visible larvae were counted manually every $20 \mathrm{~min}$. Due to those experiments, a two hour period was determined as the adequate time for healthy $C$. riparius to dig entirely into the sediment and to show natural behaviour. Second, the recapture rate of 100 C. riparius $\mathrm{L} 4$ larvae burrowed in quartz sediment was observed (replicated nine times). The recapture rate was $97.2 \%$. Third, the feeding rate of $D$. rerio with 100 introduced $C$. riparius larvae was determined. After $2 \mathrm{~h}$, the average number of surviving chironomids was between 50 and 60 individuals. With this medial number of surviving chironomids in the control treatment it is possible to detect both, an increase or decrease in feeding rate. Therefore in the main experiment we chose 100 chironomids as an adequate number for the predator-prey experiments.

\section{Main experiments}

In this study, three different treatments and one negative control were investigated:

1. Predator pre-exposed (Dc D. rerio contaminated)

2. Prey pre-exposed (Cc C. riparius contaminated)

3. Predator and prey pre-exposed (Bc Both (fish and chironomids) contaminated)

All treatments were replicated three times. In every replicate five $D$. rerio as predators and $100 C$. riparius as prey were introduced. A total of 100 chironomids per replicate were collected randomly and transferred for exposure into large glass dishes $(15 \mathrm{~cm}$ diameter, depth $8 \mathrm{~cm}$ ) containing $50 \mathrm{~g}$ of quartz sediment and the corresponding chlorpyrifos solution made from dechlorinated tap water. After $2 \mathrm{~h}$, the chironomids were transferred into 101 aquaria containing $400 \mathrm{~g}$ quartz sediment (corresponding to a $1-2 \mathrm{~cm}$ thick layer) and 81 of a mixture of dechlorinated tap water and distilled water to obtain a 
conductivity of $400-450 \mu \mathrm{s} / \mathrm{cm}$, optimal for $D$. rerio cultivation. During the transfer of the test organisms into the feeding aquaria special attention was paid to ensure that neither contaminated sediment nor water were transferred. In the $2 \mathrm{~h}$ following the transfer the chironomids had the opportunity to burrow into the sediment.

Meanwhile, five D. rerio per replicate were transferred into 41 aquaria containing 31 of the respective chlorpyrifos solution or control water. All aquaria were wrapped with a black cover to avoid disturbances from human presence. The fish were exposed for $2 \mathrm{~h}$ to the CHP contaminant.

Before the transfer of $D$. rerio into the 101 aquaria with the $C$. riparius larvae, the numbers of chironomids completely visible at the surface and those partly visible were counted. After the transfer, the fish had $2 \mathrm{~h}$ to forage and feed on $C$. riparius.

After these $2 \mathrm{~h}$ periods, the number of chironomids completely at the surface and those partly visible was recounted. Then, the fish were removed and anaesthetised with benzocain (3-5 $\mathrm{ml}$ of $40 \mathrm{mg}$ Bencocain/ml Aceton). The total length of each fish was measured with a sliding calliper (powerfix EMC, model number Z11155, resolution $0.01 \mathrm{~mm}$ ). Subsequently, surviving chironomids were searched and counted in the 101 aquaria and the sediment.

\section{Data analysis}

Nonparametric methods were chosen for the analysis because the data were only partially normally distributed (Shapiro-Wilk Test, JMP 4.0, SAS systems, USA). The data from all tests were analysed for significance using Friedman's ANOVA (Statistica 5.0, StatSoft, USA), followed by a Wilcoxon two group test (equivalent to MannWhitney test, JMP 4.0, SAS systems, USA) to examine differences between control and exposure treatments.

\section{Results}

The average total length of the zebrafish was $27.93 \pm$ $3.95 \mathrm{~mm}$ (see Table 1). There were no significant size differences between the various treatments (Friedman's

Table 1 Total length of D. rerio $(\mathrm{mm})($ mean $\pm \mathrm{SD})$

\begin{tabular}{lcrrr}
\hline & Treatment & & & \\
\cline { 2 - 5 } & Control & \multicolumn{1}{c}{ Cc } & \multicolumn{1}{c}{ Dc } & \multicolumn{1}{c}{ Bc } \\
\hline Mean & 28.42 & 27.60 & 28.34 & 27.36 \\
SD & 3.47 & 4.13 & 4.60 & 3.64 \\
\hline
\end{tabular}

No significant difference was found in $D$. rerio size between the different treatments. Treatments: $C c C$. riparius contaminated, $D c D$. rerio contaminated, $B c$ both (fish and chironomids) contaminated

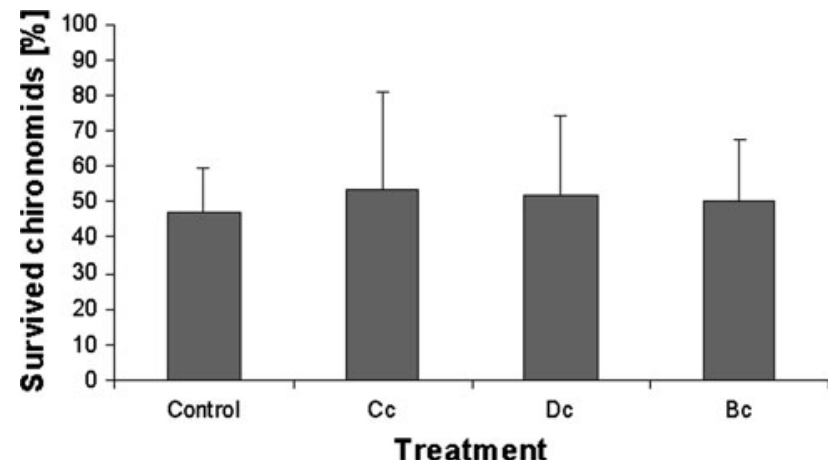

Fig. 1 Feeding rate [\%] of D. rerio on larval chironomids after $2 \mathrm{~h}$. Fish and/or chironomids were exposed to $1 \mu \mathrm{g} / \mathrm{l} \mathrm{CHP}$ for $2 \mathrm{~h}$ prior to the feeding trials. Treatments: $C c C$. riparius contaminated, $D c D$. rerio contaminated, $B c$ Both (fish and chironomids) contaminated, $n=3$, bars represent means $\pm \mathrm{SD}$

Anova n.s.). At a nominal concentration of $1 \mu \mathrm{g} / \mathrm{l}$ of CHP no significant difference between the treatments was observed (Fig. 1). No changes in the numbers of burrowed chironomids, of chironomids partly at the surface and of chironomids remaining at the sediment surface occurred neither before the introduction of the fish into the feeding aquaria nor after the removal of the fish (Friedman's Anova n.s., respectively; data not shown). Also no significant difference was found in the feeding rate of $D$. rerio preying on $C$. riparius exposed to $1 \mu \mathrm{g} / \mathrm{l} \mathrm{CHP}$ in neither of the treatments (Fig. 1).

At a nominal concentration of $6 \mu \mathrm{g} / \mathrm{l} \mathrm{CHP}$ the burrowing behaviour of exposed $C$. riparius was significantly changed compared to the burrowing behaviour of nonexposed chironomids before the introduction of the fish. Here the number of $C$. riparius remaining completely at the sediment surface was significantly increased (Wilcoxon Cc $P=0.0495$, Bc $P=0.0495$ ) (Fig. 2). Consequently, a

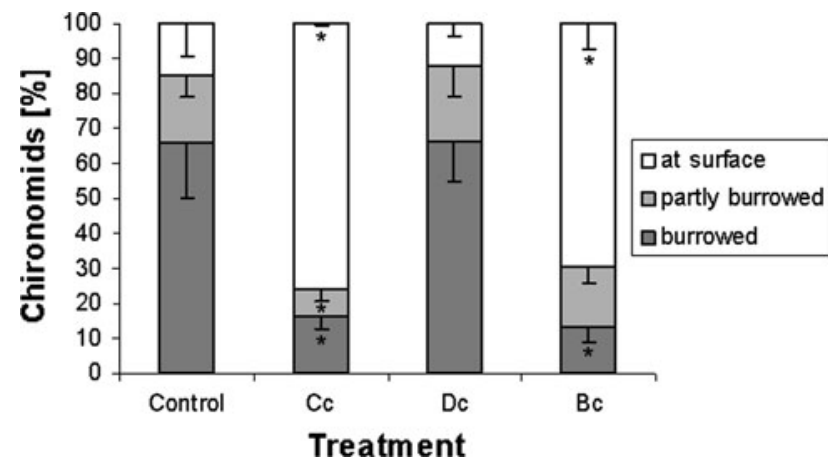

Fig. 2 Percentage of chironomids at the sediment surface, partly burrowed and totally burrowed before introducing the zebrafish. Fish and/or chironomids were exposed to $6 \mu \mathrm{g} / \mathrm{l} \mathrm{CHP}$ for $2 \mathrm{~h}$ prior to the feeding trials. Treatments: $C c C$. riparius contaminated, Dc D. rerio contaminated, $B c$ Both (fish and chironomids) contaminated. * Significantly different to the control, $P<0.05, n=3$, bars represent means $\pm \mathrm{SD}$ 


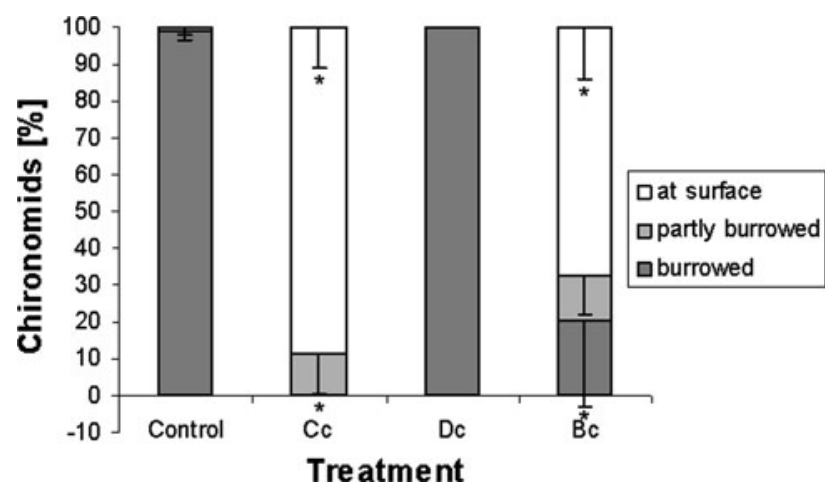

Fig. 3 Percentage of chironomids at the surface, partly burrowed and totally burrowed after introducing zebrafish. Fish and/or chironomids were exposed to $6 \mu \mathrm{g} / \mathrm{l} \mathrm{CHP}$ prior to the feeding trials. Treatments: $C c$ $C$. riparius contaminated, $D c D$. rerio contaminated, $B c$ Both (fish and chironomids) contaminated. * Significantly different to the control, $P<0.05, n=3$, bars represent means $\pm \mathrm{SD}$

significantly decreased number of larvae were partly and fully burrowed compared to the number of unexposed chironomids. No significant difference occurred between the burrowing behaviour of unexposed (Control vs Dc) or exposed chironomids ( $\mathrm{Cc} v \mathrm{Bc}$ ), respectively. After the introduction of zebrafish, a majority of the surviving $C$. riparius in the control and the $\mathrm{Bc}$ treatment were burrowed in the sediment (Fig. 3). Compared to that, the number of exposed $C$. riparius $(\mathrm{Cc}$ and $\mathrm{Bc})$ at the surface was significantly increased (Fig. 3) (Wilcoxon Cc $P=0.037$, Bc $P=0.037)$.

Comparing the number of burrowed chironomids before and after the introduction of the fish, significantly more animals were completely burrowed in the control treatment, as well as in the treatments where only the zebrafish were contaminated (Wilcoxon, $P=0.046$ and $P=0.046$, respectively) (Figs. 2 and 3). However, in the treatment where only the chironomids were exposed a significantly less number of animals was burrowed (Wilcoxon, $P=0.037)$ and when both, predator and prey, were exposed, no significant difference in the number of burrowed chironomids before and after the introduction of the fish was observable.

At the $6 \mu \mathrm{g} / \mathrm{l}$ CHP level the feeding rate of nonexposed $D$. rerio on exposed $C$. riparius was significantly increased compared towards the control (Wilcoxon $P=0,0495$ ) (Fig. 4).

\section{Discussion}

The integrity of ecosystems can be influenced by stressors on many different levels. Most studies have focused on the direct effects of contaminants on single species. For example it is known that CHP acts on the nervous system

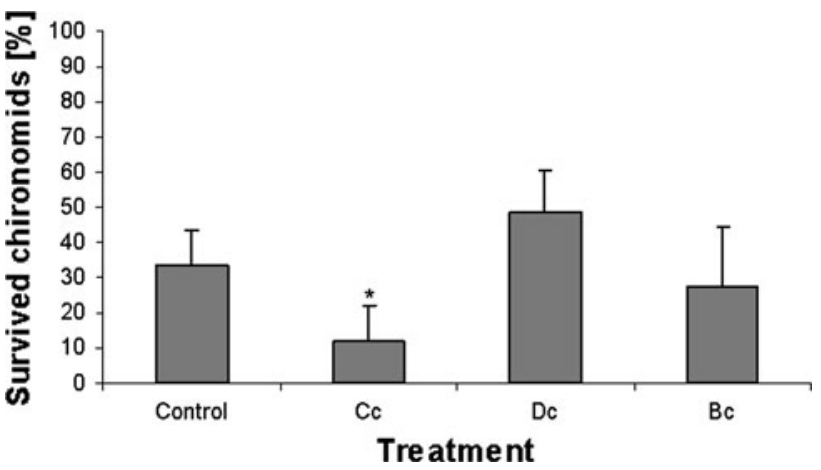

Fig. 4 Feeding rate [\%] of Danio rerio on larval chironomids after $2 \mathrm{~h}$. Fish and/or chironomids were exposed to $6 \mu \mathrm{g} / \mathrm{l} \mathrm{CHP}$ for $2 \mathrm{~h}$ prior to the feeding trials. Treatments: $C c C$. riparius contaminated, $D c D$. rerio contaminated, $B c$ Both (fish and chironomids) contaminated. * Significantly different to the control, $P<0.05, n=3$, bars represent means $\pm \mathrm{SD}$

as an inhibitor of the enzyme acetylcholinesterase (Kamrin 1997). The toxicity of chlorpyrifos has been mainly assessed during the early life stages of zebrafish (e.g. Kienle et al. 2009; Levin et al. 2003, 2004; Roex et al. 2002; Scheil and Köhler 2009), where effectively imparing concentrations were $10 \mu \mathrm{g} / \mathrm{l}$ for locomotor activity and $250 \mu \mathrm{g} / \mathrm{l}$ for morphological abnormalities (Kienle et al. 2009). For adult freshwater fish, $96 \mathrm{~h} \mathrm{LC}_{50}$ values ranged from $9 \mu \mathrm{g} / \mathrm{l}$ for adult rainbow trout to $331 \mu \mathrm{g} / \mathrm{l}$ for fathead minnow (Kamrin 1997; U.S.-EPA 1986). The effects of chlorpyrifos on chironomids have been assessed in various studies (Ankley et al. 1994; Belden and Lydy 2000; Callaghan et al. 2001; Fisher et al. 2000; Jin-Clark et al. 2002; Lydy et al. 1999; Moore et al. 1998; Schuler et al. 2005). For Chironomus tentans effective concentrations, for the single substance, were found to be at $0.3 \mu \mathrm{g} / \mathrm{l}\left(48 \mathrm{~h} \mathrm{LC}_{50}\right)$ (Moore et al. 1998) and $0.07 \mu \mathrm{g} / 1\left(10 \mathrm{~d} \mathrm{LC}_{50}\right)$ (Ankley et al. 1994), The $\mathrm{EC}_{50}$ for abnormal swimming movements was $0.39-0.49 \mu \mathrm{g} / \mathrm{l}$ for chlorpyrifos (Belden and Lydy 2000; Jin-Clark et al. 2002). In the present study, the observed effects on predator prey relationship between zebrafish and chironomids can presumably be attributed to the neurotoxic mode of action of chlorpyrifos resulting in behavioural changes.

In the present study interactions between representatives of two trophic levels and different habitats, chironomids as benthic detritus feeders and fish as pelagic secondary consumers, were investigated. The main exposure route for aquatic ecosystems is pesticide spray drift or runoff after a rain event following pesticide application. Therefore in stream systems, mainly short-time pollutant pulses occur. Regarding sediment exposure, chlorpyrifos exhibits a high affinity to sediments and a potential adsorption to sediment particles should not be omitted (Gilliom et al. 2006; Kamrin 1997). In such a situation, chironomids might be 
exposed even longer. Our study simulated pulse exposures both at low and high doses. Concentrations of up to $0.3 \mu \mathrm{g}$ $\mathrm{CHP} / \mathrm{l}$ water have been measured in aquatic systems (Gilliom et al. 2006). Schulz (2001) detected maximum chlorpyrifos concentrations of $924 \mu \mathrm{g} / \mathrm{kg}$ CHP in the sediment after a single rainstorm event in the Lourens River, South Africa, whereas concentrations in the water were only $0.2 \mu \mathrm{g} / \mathrm{l} \mathrm{CHP}$, which indicates, that CHP rapidly binds to sediment and therefore might pose a high risk for sediment inhabiting organisms such as chironomids as well as for organisms feeding on them.

When examining the burrowing behaviour of chironomids and the foraging behaviour of zebrafish exposed to $1 \mu \mathrm{g} / \mathrm{l} \mathrm{CHP}$, neither the natural behaviour of $C$. riparius nor the feeding rate of the fish seemed to be impaired by the pollutant in our study. This might result from the low concentration and short exposure time of these organisms to CHP. The highest tested CHP concentration of $6 \mu \mathrm{g} / \mathrm{l}$ could occur in water after a rain event following pesticide application, as high concentrations of CHP can be expected over a short period of time (pulse pollution). At this concentration $(6 \mu \mathrm{g} / \mathrm{l})$, CHP impaired the ability of the exposed chironomids to show natural burrowing behaviour. In these treatments a major part of the chironomids stayed at the sediment surface instead of burrowing. Therefore, they seemed to be better detectable and more easily preyed upon by the unexposed D. rerio (Cc) (Fig. 4). Accordingly, our first hypothesis ('Exposed chironomids are burrowing less than control animals, and are therefore more susceptible to predation by fish.') was verified. In choice-experiments, Hershey (1987) found that predators consistently selected chironomids which spent more time out of their tube.

In the treatments with non-exposed chironomids (control and Dc), the introduced fish seemed to trigger an increase in burrowing behaviour. The proportion of chironomids at the sediment surface was almost reduced to zero (Fig. 3). Such a behaviour has been observed with chironomid larvae exposed to fish-borne chemical cues (kairomones) simulating increasing predator densities (Hölker and Stief 2005). It can be assumed that those chironomids which had burrowed escaped from the presence of fish and survived. In the treatment with only zebrafish exposed, the feeding rate as well as the number of burrowed chironomids resembled that in the control treatment (Fig. 3). Thus, our second hypothesis ('Predation by fish leads to increased burrowing behaviour of chironomids in exposed as well as control animals.') was, in part, proven true. This is due to the fact that significantly more chironomids were burrowed in the control and the Dc treatment after having been exposed to fish, compared to the situation without fish (Figs. 2 and 3). The significantly reduced number of animals burrowed in the Cc treatment, after fish predation, indicates an easier capture of those animals by fish. This might be interpreted as a result of a reduced ability to burrow presumably due to increased convulsions caused by the effects of chlorpyrifos on the nervous system. In the $\mathrm{Bc}$ treatment the chironomids did not (or were not able to) change burrowing behaviour due to fish predation as no significant difference in burrowed animals could be observed. Therefore finally, our third hypothesis ('When exposing predator and prey, the decreased ability of the predator to recognize the prey and of the prey to burrow are outweighed, resulting in no significant differences in feeding rate compared to the control') could be proven. This was confirmed by the similar feeding rate of zebrafish in control treaments and in the $\mathrm{Bc}$ treatment. Similar results were obtained when investigating predatorprey relationships between two amphibian species under insecticide exposure (Bridges 1999). Here predation rates did not differ from those under natural conditions when pre-exposing both, predator and prey, simultaneously.

In the literature, chironomids have been found to be an important prey object to several fish species (Forsyth and James 1988). It is known that the densities of chironomids can respond to fish predation (Gilinsky 1984). In conclusion, the results from our study imply that the biocoenosis of aquatic ecosystems might be indirectly affected due to pollutant exposure.

The effect concentration for Chironomids in our study is an order of magnitude higher compared to earlier studies with $C$. tentans exposed to chlorpyrifos, where effective concentrations of $0.3 \mu \mathrm{g} / \mathrm{l}(48 \mathrm{~h} \mathrm{LC} 50), 0.07 \mu \mathrm{g} / \mathrm{l}(10 \mathrm{~d}$ $\mathrm{LC}_{50}$ ) and $0.39-0.49 \mu \mathrm{g} / \mathrm{l}\left(96 \mathrm{~h} \mathrm{EC}_{50}\right.$ for abnormal swimming movements) were observed (Ankley et al. 1994; Belden and Lydy 2000; Jin-Clark et al. 2002; Moore et al. 1998). However, our results can be considered as even more relevant due to the short exposure time and the integrative parameters observed. The same is true for chlorpyrifos exposure to zebrafish, where subchronic effects on locomotor activity were visible at $10 \mu \mathrm{g} / \mathrm{l}$ (LOEC after 5 d exposure, Kienle et al. 2009) and chronic effects on response latency and spatial discrimination of adult zebrafish occurred after early life stage exposure to $0.1 \mu \mathrm{g} / \mathrm{l}$ chlorpyrifos for 5 days (Levin et al. 2003). Our effective concentration is again one order of magnitude higher than the one mentioned above, but with a much shorter exposure time, which might explain the deviation of the effect concentrations. Another possible reason might be differences in the experimental setup and the addressed endpoints (response latency and spatial discrimination vs feeding rate). In a previous study, the predator avoidance behaviour of chironomids in reaction to kairomones of predatory fish (Rutilus rutilus) did influence mineralization processes of organic matter (Stief and Hölker 2006). This indicates that predator-prey interactions have an impact 
even on ecosystem function. Our results suggest that simple single species ecotoxicity tests do not reflect adequately potential effects of a toxin on ecosystem structure and function. Up to now the relevance of predator-prey interactions has not been considered in chemical risk assessment, with the exception of conducted mesocosm studies. Our study shows the relevance of the mentioned problem and also proposes a simple method to quantify the effects of a toxic compound, CHP, on interactions between predator and prey organisms.

Acknowledgments We are grateful to Niels Dieter for assistance with the experimental procedure. Also the Max-Planck-Institute for Developmental Biology in Tübingen is thanked for providing the fish.

\section{References}

Ankley GT, Call DJ, Cox JS, Kahl MD, Hoke RA, Kosian PA (1994) Organic carbon partitioning as a basis for predicting the toxicity of chlorpyrifos in sediments. Environ Toxicol Chem 13:621-626

Bailey HC, Deanovic L, Reyes E, Kimball T, Larson K, Cortright K, Connor V, Hinton DE (2000) Diazinon and chlorpyrifos in urban waterways in Northern California, USA. Environ Toxicol Chem 19:82-87

Baker RL, Ball SL (1995) Microhabitat selection by larval Chironomus tentans (Diptera: Chironomidae): effects of predators, food, cover and light. Freshw Biol 34:101-106

Béchard KM, Gillis PL, Wood CM (2008) Trophic transfer of Cd from larval chironomids (Chironomus riparius) exposed via sediment or waterborne routes, to zebrafish (Danio rerio): tissuespecific and subcellular comparisons. Aquat Toxicol 90:310-321

Begon M, Townsend C, Harper J (2006) Ecology. From individuals to ecosystems. Blackwell, Malden, MA

Belden JB, Lydy MJ (2000) Impact of atrazine on organosphosphate insecticide toxicity. Environ Toxicol Chem 19:2266-2274

Börries A (2006) Das Zierfischverzeichnis: Zebrabärbling/Zebrafisch Danio rerio. http://www.zierfischverzeichnis.de/klassen/pisces/ cypriniformes/cyprinidae/danio_rerio.htm. Retrieved 15 Jun 2010

Bridges CM (1999) Predator-prey interactions between two amphibian species: effects of insecticide exposure. Aquat Ecol 33:205-211

Brown GE (2003) Learning about danger: chemical alarm cues and local risk assessment in prey fishes. Fish Fish 4:227-234

Callaghan A, Hirthe G, Fisher T, Crane M (2001) Effect of short-term exposure to chlorpyrifos on developmental parameters and biochemical biomarkers in Chironomus riparius Meigen. Ecotoxicol Environ Saf 50:19-24

Dell 'Omo G (2002) Behavioural ecotoxicology. Wiley, Chichester

Dow AgroSciences (2010) What is chlorpyrifos? http://www. chlorpyrifos.com/. Retrieved 15 Jun 2010

Fisher TC, Crane M, Callaghan A (2000) An optimized microtiterplate assay to detect acetylcholinesterase activity in individual Chironomus riparius Meigen. Environ Toxicol Chem 19:1749-1752

Forsyth DJ, James MR (1988) The Lake Okaro ecosystem 2. Production of the chironomid Polypedilum pavidus and its role as food for two fish species. N Z J Mar Freshwater Res 22:327-335

Gerhardt A (2007) Aquatic behavioural ecotoxicology-prospects and limitations. Hum Ecol Risk Assess 13:481-491

Gilinsky E (1984) The role of fish predation and spatial heterogeneity in determining benthic community structure. Ecology 65:455-468

Gilliom RJ, Barbash JE, Crawford CG, Hamilton PA, Martin JD, Nakagaki N, Nowell LH, Scott JC, Stackelberg PE, Thelin GP,
Wolock DM (2006) Pesticides in the nation's streams and ground water, 1992-2001: the quality of our nation's waters. U.S. Geological Survey Circular 1291

Gómez A, Cecchine G, Snell T (1997) Effect of pentachlorophenol on predator-prey interaction of two rotifers. Aquat Toxicol 37:271-282

Goyke A, Hershey A (1992) Effects of fish predation on larval chironomid (Diptera: Chironomidae) communities in an arctic ecosystem. Hydrobiologia 240:203-211

Grippo MA, Heath AG (2003) The effect of mercury on the feeding behavior of fathead minnows (Pimephales promelas). Ecotoxicol Environ Saf 55:187-198

Hamers T, Krogh PH (1997) Predator-prey relationships in a twospecies toxicity test system. Ecotoxicol Environ Saf 37:203-212

Hershey AE (1987) Tubes and foraging behavior in larval Chironomidae: implications for predator avoidance. Oecologia 73:236-241

Hölker F, Stief P (2005) Adaptive behaviour of chironomid larvae (Chironomus riparius) in response to chemical stimuli from predators and resource density. Behav Ecol Sociobiol 58:256-263

Jin-Clark Y, Lydy MJ, Yan Zhu K (2002) Effects of atrazine and cyanizine on chlorpyrifos toxicity in Chironomus tentans (Diptera:Chironomidae). Environ Toxicol Chem 21:598-603

Kamrin MA (1997) Pesticide profiles: toxicity, environmental impact, and fate. Lewis Publishers, Boca Raton, New York

Kienle C, Köhler H-R, Gerhardt A (2009) Behavioural and developmental toxicity of chlorpyrifos and nickel chloride to zebrafish (Danio rerio) embryos and larvae. Ecotoxicol Environ Saf 72:1740-1747

Lawrence C (2007) The husbandry of zebrafish (Danio rerio): a review. Aquaculture 269:1-20

Levin ED, Chrysanthis E, Yacisin K, Linney E (2003) Chlorpyrifos exposure of developing zebrafish: effects on survival and longterm effects on response latency and spatial discrimination. Neurotoxicol Teratol 25:51-57

Levin ED, Swain HA, Donerly S, Linney E (2004) Developmental chlorpyrifos effects on hatchling zebrafish swimming behavior. Neurotoxicol Teratol 26:719-723

Lima SL (2002) Putting predators back into behavioral predator-prey interactions. Trends Ecol Evol 17:70-75

Lydy MJ, Belden JB, Ternes MA (1999) Effects of temperature on the toxicity of M-parathion, chlorpyrifos, and pentachlorobenzene to Chironomus tentans. Arch Environ Contam Toxicol 37:542-547

Macchiusi F, Baker RL (1992) Effects of predators and food availability on activity and growth of Chironomus tentans (Chironomidae: Diptera). Freshw Biol 28:207-216

Moore MT, Huggett DB, Gillespie JWB, Rodgers JJH, Cooper CM (1998) Comparative toxicity of chlordane, chlorpyrifos, and aldicarb to four aquatic testing organisms. Arch Environ Contam Toxicol 34:152-157

Nyholm JR, Norman A, Norrgren L, Haglund P, Andersson PL (2008) Maternal transfer of brominated flame retardants in zebrafish (Danio rerio). Chemosphere 73:203-208

OECD (1992) OECD Guideline for testing of chemicals 203: Fish, Acute Toxicity Test

Pinder LCV (1986) Biology of freshwater Chironomidae. Annu Rev Entomol 31:1-23

Power ME (1990) Effects of fish in river food webs. Science 250:811-814

Rahel FJ, Stein RA (1988) Complex predator-prey interactions and predator intimidation among crayfish, piscivorous fish, and small benthic fish. Oecologia 75:94-98

Richardson RJ (1995) Assessment of the neurotoxic potential of chlorpyrifos relative to other organophosphorus compounds: a critical review of the literature. J Toxicol Environ Health 44:135-165 
Roex EWM, de Vries E, van Gestel CAM (2002) Sensitivity of the zebrafish (Danio rerio) early life stage test for compounds with different modes of action. Environ Pollut 120:355-362

Scheil V, Köhler H-R (2009) Influence of nickel chloride, chlorpyrifos, and imidacloprid in combination with different temperatures on the embryogenesis of the Zebrafish Danio rerio. Arch Environ Contam Toxicol 56:238-243

Schuler L, Trimble A, Belden J, Lydy M (2005) Joint toxicity of triazine herbicides and organophosphate insecticides to the midge Chironomus tentans. Arch Environ Contam Toxicol 49:173-177

Schulz R (2001) Rainfall-induced sediment and pesticide input from orchards into the lourens river, western cape, south Africa: importance of a single event. Water Res 35:1869-1876

Schulz R, Dabrowski JM (2001) Combined effects of predatory fish and sublethal pesticide contamination on the behavior and mortality of mayfly nymphs. Environ Toxicol Chem 20:2537-2543

Sheipline R (1993) Background information on nine selected pesticides. California Regional Water Quality Control Board, Sacramento

Sih A (1982) Foraging strategies and the avoidance of predation by an aquatic insect, Notonecta hoffmanni. Ecology 63:786-796
Stief P, Hölker F (2006) Trait-mediated indirect effects of predatory fish on microbial mineralization in aquatic sediments. Ecology 87:3152-3159

Taylor EJ, Morrison JE, Blockwell SJ, Tarr A, Pascoe D (1995) Effects of lindane on the predator-prey interaction between Hydra oligactis Pallas and Daphnia magna Strauss. Arch Environ Contam Toxicol 29:291-296

Thorp JH, Bergey EA (1981) Field experiments on interactions between vertebrate predators and larval midges (Diptera: Chironomidae) in the littoral zone of a reservoir. Oecologia 50:285-290

Townsend C, Harper J, Begon M (2003) Ökologie. Springer-Verlag, Berlin

Tseng M (2003) Life-history responses of a mayfly to seasonal constraints and predation risk. Ecol Entomol 28:119-123

U.S.-EPA (1986) Ambient water quality criteria for chlorpyrifos. Office of Water, Washington, DC

Weis JS, Samson J, Zhou T, Skurnick J, Weis P (2001) Prey capture ability of mummichogs (Fundulus heteroclitus) as a behavioral biomarker for contaminants in estuarine systems. Can J Fish Aquat Sci 58:1442-1452 